\title{
Impact of climate change on agricultural crops yield on the territory of the Republic of Armenia
}

\author{
Varduhi Margaryan 1, *, Gennady Tsibulskii ${ }^{2}$ and Elena Fedotova ${ }^{3}$ \\ ${ }^{1}$ Yerevan State University, Department of Physical Geography and Hydrometeorology, Faculty of \\ Geography and Geology, Yerevan, Armenia \\ ${ }^{2}$ Siberian Federal University, Institute of Space and Information Technologies, Chair of Systems of \\ Artificial Intelligence, 660074 Kirenskogo St. 26, Krasnoyarsk, Russian Federation \\ ${ }^{3}$ Sukachev Institute of forest SB RAS, FRC KSC SB RAS, 660036 Academgorodok 50, Krasnoyarsk, \\ Russian Federation
}

\begin{abstract}
The article assesses the change in air temperature and precipitation, and also examines the impact of climate change on crop yields in the Republic of Armenia. As a source of information, the actual data of agrometeorological observations of the GEO "Center for Hydrometeorology and Monitoring" of the Ministry of Environment of the Republic of Armenia and the National Statistical Service are used. As a result of the study, it turned out that there are trends towards an increase in the average annual values of air temperature and heat provision of crops (in total temperatures above $10.0^{\circ} \mathrm{C}$ ). In the studied area, there are no regular changes in the amount of atmospheric precipitation over the year. The impact of climate change will only worsen and lead to various problems in water industry, agriculture, energy, health and other sectors. In the republic in 2000-2018 are observed of both the gross harvest and agricultural crops yield increase, with the exception of the tobacco crop. However, this does not mean that agricultural crops are not affected by climate change.
\end{abstract}

\section{Introduction}

The climate has a decisive influence on agricultural production. Human activities affect the climate, and this factor is unlikely to weaken in the future. Agriculture also has this impact, which at the same time has significant potential for climate change mitigation. Climate changes in farming can generate transformation of crop growth (development stages and their duration), changes of agro-climatic zone's borders, even it is possible to push out the some crops from this area or import of new types of crops [7].

Agriculture is the sector of the economy that is most dependent on the climate. It should be noted that agriculture is one of the main sectors of the Armenian economy, it accounts for about $20 \%$ of GDP, and together with the processing of agricultural products - $26 \%$. Moreover, about $60 \%$ falls on crop production. On the other hand, risks to food security are increasing due to the expected adverse effects of climate change. Therefore, the strategic task of agriculture is to improve the country's food security, ensure $75-80 \%$ of the production of basic food products, increase competitiveness, ensure sustainable development, and develop a system of preventive and adaptation measures to climate change.

Given the above, the work was aimed at studying and analyzing climate change in the study area, discussing and assessing the vulnerability of agricultural crops to climate change, reducing the negative effects of climate change and crops adaptation. 


\section{Study areas, Data and Methods}

The information and theoretical basis of this study are current researches in the field of climate change, long-term development programs, government projects and decisions, reports [1, 4-6]. As the source of information actual data of agrometeorological observations of «Hydrometeorology and Monitoring Center» SNCO of the Ministry of Environment of the Republic of Armenia and the National Statistical Service are used.

The Republic of Armenia is located in the northeast of the Armenian Highlands, at the border of the Caucasus and Western Asia. In the north, Armenia borders with Georgia, in the east - Azerbaijan, in the west and southwest - Turkey, and in the south - Iran. The territory of the Republic of Armenia covers $29743 \mathrm{~km}^{2}$. Armenia is a mountainous country: $76,5 \%$ of the territory is in the altitudes of $1000-2500 \mathrm{~m}$ above sea level. According to the 2006 Land Balance of Armenia, agricultural land accounts for $69 \%$, forest $-11,5 \%$, specially protected areas of nature $-12,4 \%$, wetlands $-0,9 \%$, settlements, industries, communications, transport and utility infrastructure $-5,4 \%$, and other land types $-1,7 \%$ of the territory of Armenia [2].

Armenia is a country of climatic contrasts: due to intricate terrain, even in a small territory, a wide variety of climates can be found. The country has almost all types of climate, from arid subtropical to cold high mountainous climates. The average annual ambient air temperature is $5,5^{\circ} \mathrm{C}$. The average annual temperature is below zero in altitudes above 2500 $\mathrm{m}$. The summer is temperate: the temperature at the end of July is $16,7^{\circ} \mathrm{C}$. The recorded absolute highest temperature is $43,7^{\circ} \mathrm{C}$. Winters are cold. January is the coldest winter month, with an average temperature of $-6,7^{\circ} \mathrm{C}$. The recorded absolute lowest temperature is $-42,0^{\circ} \mathrm{C}$. Winters in the northeastern and southeastern parts of the country are temperate. The average annual precipitation amounts to $592 \mathrm{~mm}$.

As a methodological basis used are: statistical analysis, correlation methods, modelling.

\section{Results and discussion}

Climate has a direct impact on an agricultural crops growth and yield. Among climatic conditions, temperature is an especially important factor in the viability of crops. The total value of active temperatures in the growing season in general characterizes the probability of growing crops in a given territory, as well as, in particular, the average period and duration of crops phases during the vegetation period. For example [9], grape vegetation begins in spring with sap flow, when the average daily air temperature exceeds $8-10^{\circ} \mathrm{C}$ and ends in autumn with an average daily temperature below $8-10^{\circ} \mathrm{C}$. In $15-25$ days after sap flow, when the average daily temperature passes through $11-12^{\circ} \mathrm{C}$, the buds open, flowering occurs $35-57$ days after the buds open, when the average daily temperature is $18-21^{\circ} \mathrm{C}$.

Studies show that according to the actual monitoring data, mainly in the area observed upward trend in average annual air temperature values (fig. 1, a, b). 

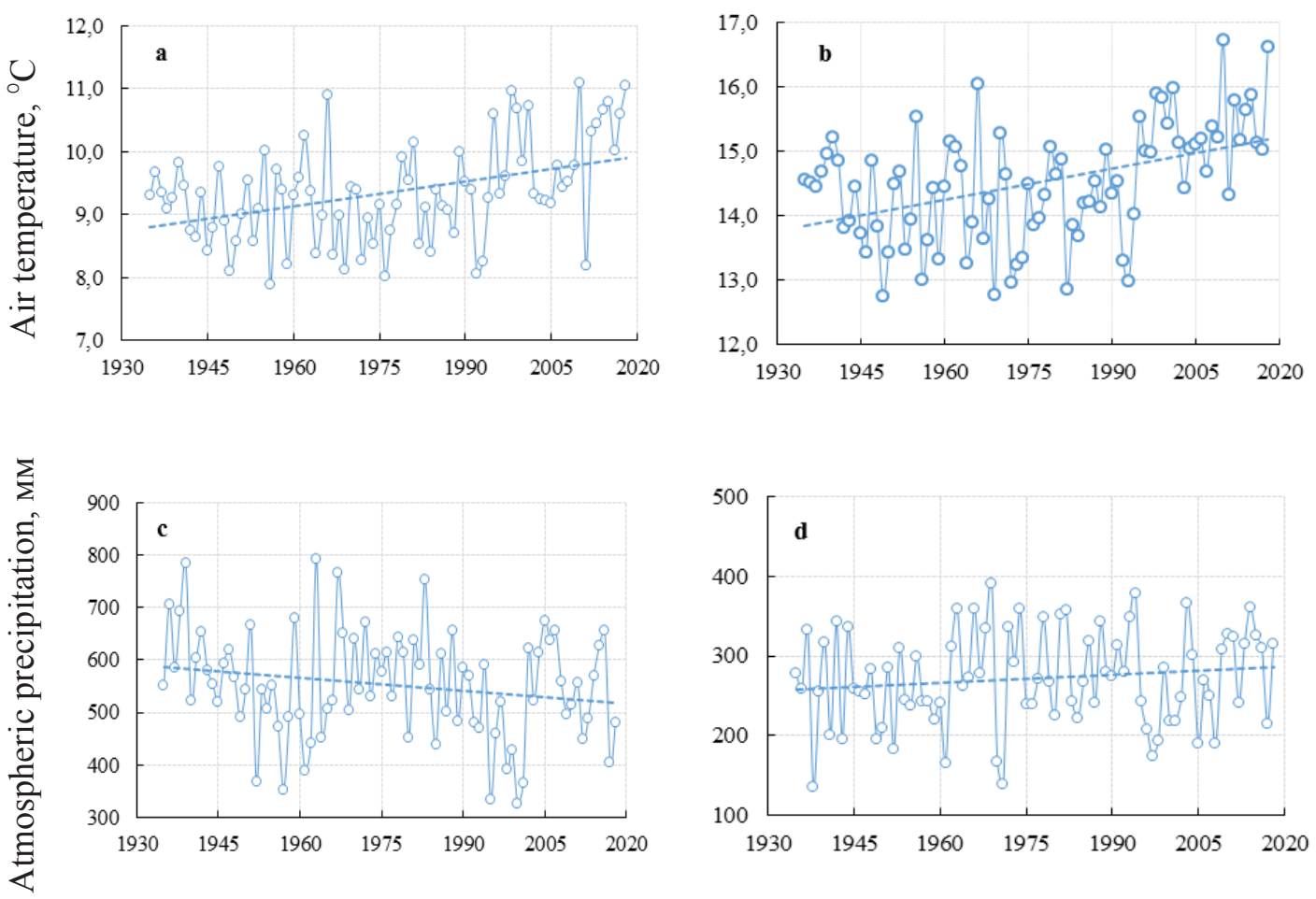

Year

Fig. 1. Long-term changes of average air temperature $(a, b)$ and atmospheric precipitation $(c, d)$ for year for stations Odzun (north of Armenia, $1105 \mathrm{~m}$ above s.l.) (a, c) and Meghri (south of Armenia, $627 \mathrm{~m}$ above s.1.) (b, d).

It should be noted, that the maximum rate of temperature increas is observed in the summer months. In the republic also a tendency of agricultural crops the heat provision increase (the sum of temperatures above $10,0{ }^{\circ} \mathrm{C}$ ) is observed [9]. Heat provision of agricultural crops is the amount of heat needed to complete the annual cycle of a crop development. It is expressed with the sum of average daily temperatures (the amount of biological temperatures), which accumulate from the beginning of vegetation to a crop maturity. Heat provision has certain effect on a sugar accumulation in fruit, and thus the variety choice, and specialization in viticulture.

With regard to precipitation, the area under study does not show regular changes in the amount of precipitation during the year. For annual precipitation, for different areas both negative and positive trends are observed (Fig. 1, c, d). However, it should be noted that a significant decrease in precipitation in summer is mainly expected.

According to [3], over the period of 1929-1996, the annual average temperature increased by $0,4^{\circ} \mathrm{C}$, during $1929-2007$ - by $0,85^{\circ} \mathrm{C}$, during $1929-2012$ - by $1,03^{\circ} \mathrm{C}$, and during 1929 2016 - by $1,23^{\circ} \mathrm{C}$. The ambient air temperature change has had different trends in different seasons. During the period of 1966-2016, the average summer temperature increased by about $1,3^{\circ} \mathrm{C}$, moreover, over the last century, extremely hot summers were observed in Armenia within the last 20 years. During the period of 1935-1996, the average annual precipitation decreased by $6 \%$ and in $1935-2016$ - by about $9 \%$. The spatial distribution of 
precipitation is quite irregular. During the period of 1935-2016 the climate in the north, south and central regions of the country has become more arid, while precipitations have increased in the Shirak plain, in the Lake Sevan basin and in the Aparan-Hrazdan regions. The results of the CCSM4 Global Climate Model used and reported in the NC3 were reviewed for the projection of changes in air temperature and atmospheric precipitation, as well as high resolution METRAS (12x12 km) regional climate model was applied [3]. The average annual temperature across the territory of Armenia is projected to increase by up to $1,6^{\circ} \mathrm{C}$ by 2040 , by $3,3^{\circ} \mathrm{C}$ - by 2070 and by $4,7^{\circ} \mathrm{C}$ - by 2100 , relative to the baseline annual average $\left(5,5^{\circ} \mathrm{C}\right)$ for $1961-1990$. As for atmospheric precipitations, these are projected to decline by up to $2,7 \%$ by $2040,5,4 \%$ - by 2070 and $8,3 \%$ - by 2100 , relative to the baseline annual average $(592 \mathrm{~mm})$ for 1961-1990. It should be noted that there are significant uncertainties in global precipitation assessments due to its high variability and the large number of affecting factors. The issue related to uncertainties in projecting precipitation changes has also been highlighted in the 5th IPCC Report [5].

Therefore, it appears, that the summer season in most regions of the country (hence the vegetation period) is characterized by hot and dry weather conditions. The impact of climate change will only get worse and lead to the generation of various problems in water industry, agriculture, energy, health and other sectors.

On the other hand, it should be noted that the analysis of statistical data shows (table 1), that in the area of the republic in 2000-2018 observed of both the gross harvest and agricultural crops yield increase (fig. 2), with the exception of the tobacco crop. In the Republic, growth of gross harvest and yield of grapes is observed during 2000-2015 [8]. However, this does not mean that agricultural crops are not vulnerable to the impacts of climate change. However, a comprehensive and systematic study of complex events is required.

Table 1. Gross harvest and yield capacity of main agricultural crops for the period 2000-2018

\begin{tabular}{|l|c|c|l|c|c|}
\hline \multicolumn{1}{|c|}{$\begin{array}{c}\text { Agricultural } \\
\text { crops }\end{array}$} & $\begin{array}{c}\text { Gross harvest, } \\
\text { 1 000. t }\end{array}$ & $\begin{array}{c}\text { Yield capacity, } \\
\text { centners / ha }\end{array}$ & $\begin{array}{c}\text { Agricultural } \\
\text { crops }\end{array}$ & $\begin{array}{c}\text { Gross harvest, } \\
1000 \mathrm{t}\end{array}$ & $\begin{array}{c}\text { Yield capacity, } \\
\text { centners / ha }\end{array}$ \\
\hline $\begin{array}{l}\text { Winter and } \\
\text { spring wheat* }\end{array}$ & 245,9 & 24,5 & Legumes* & 4,76 & 23,5 \\
\hline $\begin{array}{l}\text { Winter and } \\
\text { spring barley* }\end{array}$ & 132,3 & 20,6 & Tobacco & 1,5 & 26,5 \\
\hline $\begin{array}{l}\text { Maize for } \\
\text { grain* }\end{array}$ & 15,4 & 51,9 & Potatoes & 540,1 & 177,6 \\
\hline Oats* & 3,14 & 19,8 & Vegetables & 739,0 & 290,5 \\
\hline Spelt* & 9,62 & 16,9 & Grape & 190,5 & 128,3 \\
\hline
\end{tabular}

*weight after processing

In order to assess the impact of climate on the productivity of agricultural crops, numerous correlations between air temperature and various crops were obtained, using the corresponding data of the last 10-15 years. As an example, the paper presents correlations between the average air temperature in July and average crop capacity grain and leguminous crops (fig. 3, a), the average air temperature in March and average crop capacity of vegetable crops (fig. 3, b) for the Armavir marz. Between air temperature and agricultural crops, both directly proportional (fig. 3, a) and inversely proportional (fig. 3, b) correlations were obtained. Moreover, the obtained connections are not close and cannot be used in calculating the yield of agricultural crops. This is because the yield of agricultural crops is formed under the influence of various, including joint weather and climatic factors. 

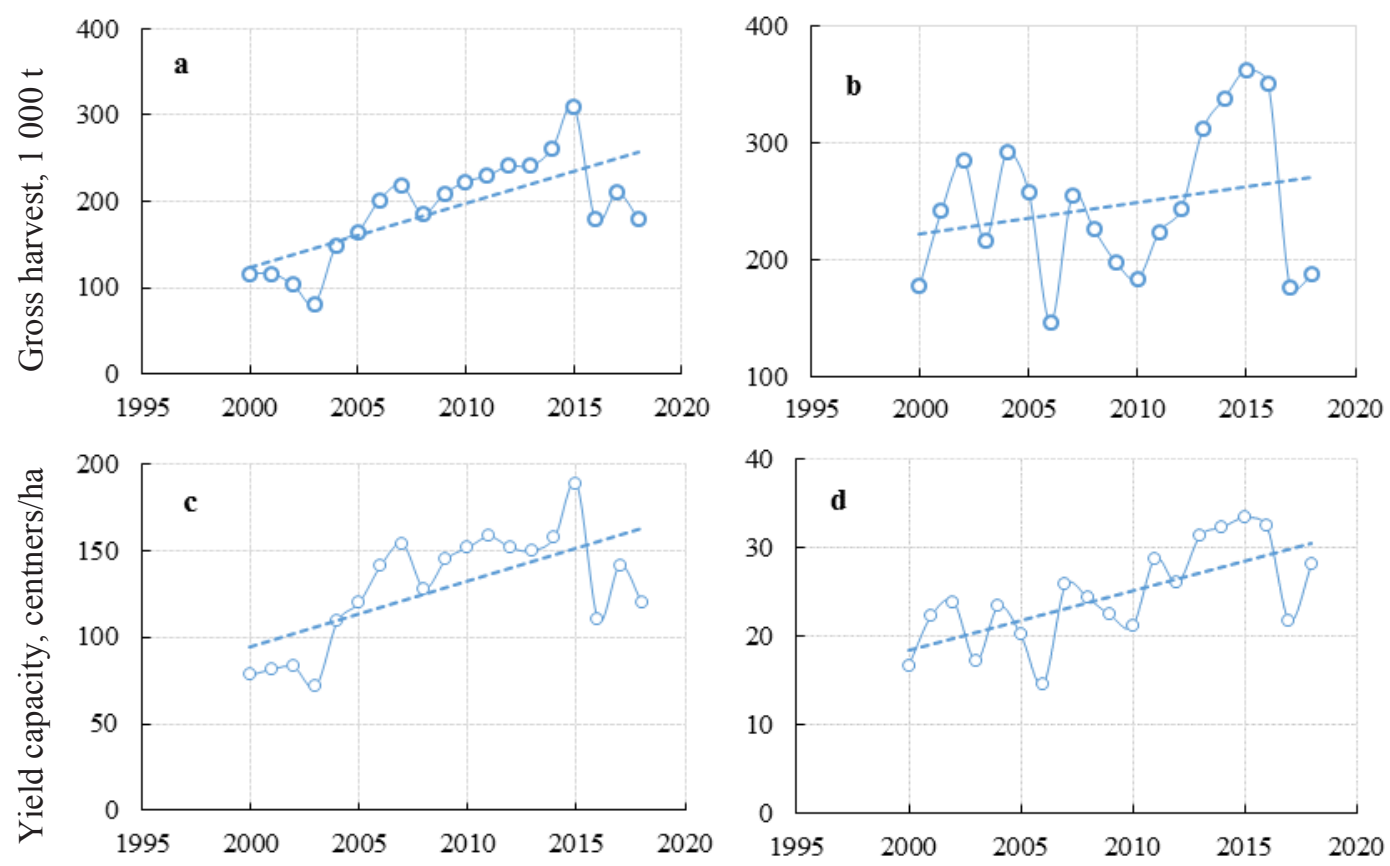

\section{Year}

Fig. 2. Long-term changes of gross harvest (1 $000 \mathrm{t}$ ) and yield capacity (centners/ha) for grape (a, c), winter and spring wheat $(b, d)$.
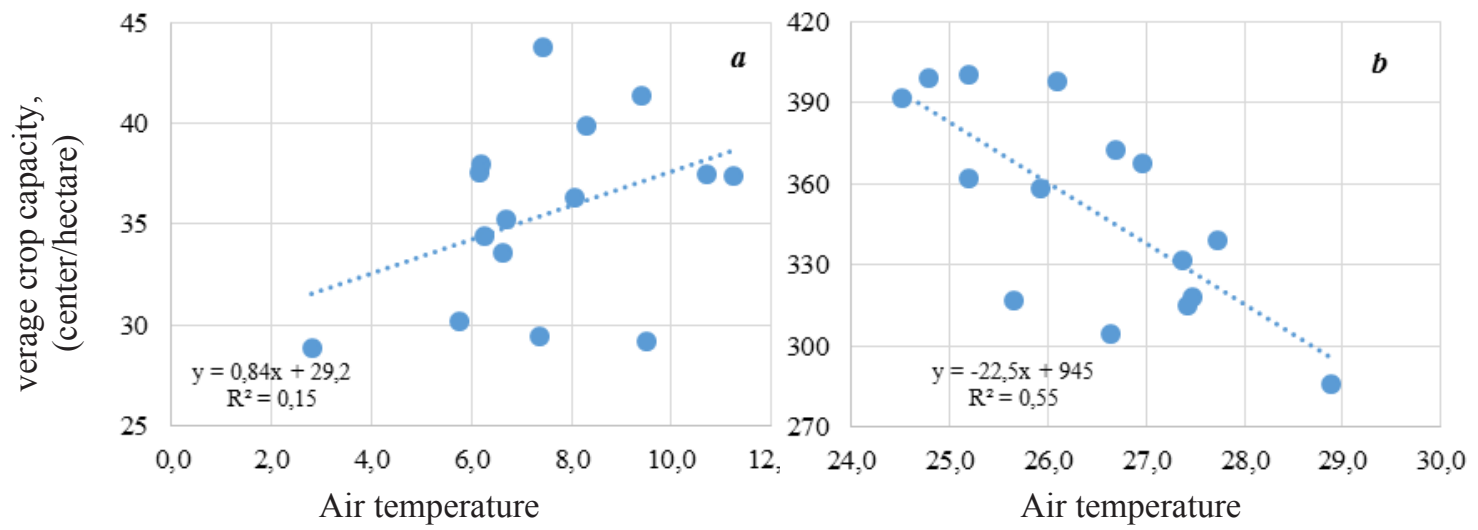

Fig. 3. Correlations between the average air temperature in July and average crop capacity of grain and leguminous crops (a), the average air temperature in March and average crop capacity of vegetable crops (b) for the Armavir marz. 


\section{Conclusions}

Thus, we arrive to the following conclusions from the studies and recommendations based on them on the territory of the Republic Armenia:

- tendency to increase annual average temperature and of agricultural crops heat provision is observed;

- there are no regular changes in the amount of atmospheric precipitation per year, that is, for the annual amount of precipitation there are both positive and negative trends.;

- in 2010-2018 in the region mainly there was an increase in gross crop harvesting and crop growth.

However, this does not mean that agricultural crops are not vulnerable to the impacts of climate change. There is required implementation of a comprehensive and systematic study of complex events.

- The climate has a direct impact on an agricultural crops growth and yield. The impact of climate change will only get worse and lead to the generation of various problems agriculture and other sectors;

- The agricultural crops are most vulnerable to climate change in the low (irrigated and rain-fed conditions) and middle (dry conditions) zones.

It is necessary to carry out work in the following directions:

- Adaptation of new plants to growing conditions throughout the system running;

- Expansion of irrigated land zones, up to 2000-2200 m, additional irrigation water provided;

- $\quad$ Effective water use technologies, especially in irrigation of fields;

- Drought-resistant and highly productive varieties of agricultural crops selection and implementation of the existing varieties import and localization;

- Investment in infrastructure in the fight against atmospheric adverse phenomena;

- The gradual introduction of the insurance system.

\section{References}

1. Agriculture sustainability and risk assessment under climate change. Global climate change and risk assessment in agriculture in Russia. (Saint-Petersburg. 2011)

2. Armenia's Third National Communication on Climate Change. (Yerevan, Lusabats. 2015)

3. Armenia's Fourth National Communication on Climate Change. (Yerevan, UNDP Armenia. 2020)

4. T.A. Goryanina, A.M. Medvedev The agrarian scientific journal. 12, 6 (2019)

5. IPCC: Climate Change 2013: The Physical Science Basis. Cambridge University Press, Cambridge, United Kingdom and New York, NY, USA (2013)

6. V.G. Margaryan, G.V. Guloyan MACSUR Science Conference. (Berlin. 2017)

7. V.G. Margaryan, G.V. Guloyan, H.S. Qocharyan International conference landscape dimensions of sustainable development: science - planning - governance. ICLDS-2017. (Tbilisi, Georgia. 2017)

8. V.G. Margaryan, M.S. Mkhitaryan MACSUR Science Conference. (Berlin. 2017)

9. V.G. Margaryan, M.S. Mkhitaryan Ukrainian hydrometeorological journal. 21, 7 (2018) 